\title{
Interactions between Resident Risk Perceptions and Wildfire Risk Mitigation: Evidence from Simultaneous Equations Modeling
}

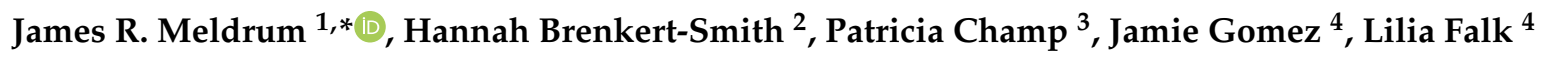 \\ and Christopher Barth ${ }^{5}$ \\ 1 Fort Collins Science Center, U.S. Geological Survey, Fort Collins, CO 80526, USA \\ 2 Institute of Behavioral Science, University of Colorado Boulder, Boulder, CO 80309, USA \\ 3 Rocky Mountain Research Station, USDA Forest Service, Fort Collins, CO 80526, USA \\ 4 West Region Wildfire Council, Montrose, CO 81401, USA \\ 5 Fire and Aviation Management, U.S. Bureau of Land Management, Billings, MT 59101, USA \\ * Correspondence: jmeldrum@usgs.gov; Tel.: +1-970-226-9176
}

Received: 29 June 2019; Accepted: 5 August 2019; Published: 12 August 2019

check for updates

\begin{abstract}
Fire science emphasizes that mitigation actions on residential property, including structural hardening and maintaining defensible space, can reduce the risk of wildfire at a home. Accordingly, a rich body of social science literature investigates the determinants of wildfire risk mitigation behaviors of residents living in fire-prone areas. Here, we investigate relationships among wildfire hazards, residents' risk perceptions, and conditions associated with mitigation actions using a combination of simulated wildfire conditions, household survey responses, and professionally assessed parcel characteristic data. We estimate a simultaneous model of these data that accounts for potential direct feedbacks between risk perceptions and parcel-level conditions. We also compare the use of self-reported versus assessed parcel-level data for estimating these relationships. Our analysis relies on paired survey and assessment data for approximately 2000 homes in western Colorado. Our simultaneous model demonstrates dual-directional interactions between risk perceptions and conditions associated with mitigation actions, with important implications for inference from simpler approaches. In addition to improving general understanding of decision-making about risk and natural hazards, our findings can support the effectiveness of publicly supported programs intended to encourage mitigation to reduce society's overall wildfire risk.
\end{abstract}

Keywords: wildland fire; risk assessment; parcel-level risk; scale; mitigation; simultaneous modeling; home ignition zone

\section{Introduction}

The fire season of 2018 demonstrated the potential scope of impacts of a wildfire disaster to residents exposed to wildfire hazards. A single fire, the Camp Fire in Paradise, California, resulted in 85 fatalities and nearly 14,000 residences destroyed (https://inciweb.nwcg.gov/incident/6250/). Residents can take action on their individual properties, including structural hardening and maintaining defensible space, that complement risk-reduction actions taken at other scales in reducing the risk of wildfire to homes. The home ignition zone (HIZ) concept was developed and is supported by data from fire experiments, fire modeling, and post-fire studies, and it indicates that whether or not a home ignites in a wildfire is largely determined by the condition, materials, and design of the structure in relation to the structure's immediate surroundings [1-7]. Defensible space, which consists of clearing vegetation and other materials near the structure both to reduce nearby fuels and to enable safe and effective fire response [8], is also widely recognized as effective at reducing risk to structures [9-14]. 
The effectiveness of mitigation work on (structural hardening) and near (defensible space) the home is further supported by the anecdotal evidence of the experiences by residents, local governments, and public land agencies, as shared by the Fire Adapted Communities Learning Network [15].

With the number of homes in the wildland-urban interface (WUI), where wildlands abut residential development, predicted to double between 2000 and 2030 [16] and increases in the size and frequency of wildfires predicted to worsen due to climate-related regional warming and changes in precipitation $[17,18]$, understanding the behavioral choices underlying mitigation-related actions becomes increasingly important. Indeed, a rich literature investigates the human dimensions of wildfire, including risk perceptions and mitigation decisions $[19,20]$. Wildfire social science research often finds risk perceptions to be correlated with risk mitigation behavior (e.g., [21-24]), but relationships among these and related variables are complex. Risk mitigation behavior has also been found to be a function of the perceived efficacy of risk mitigation actions [24-26], personal responsibility for risk mitigation [23,27], social interactions related to wildfire risk [22,26,28], as well as other factors. However, few related studies that model risk perceptions include biophysical measures of the hazard $[19,29]$, such as estimates of burn probability or conditional flame intensities, and those that do tend to rely on vegetation characteristics or fire modeling based on a relatively coarse scale compared to the parcel-level characteristics supported by fire science.

Further, a growing body of literature suggests that risk perceptions can affect mitigation behaviors, as well as vice versa. Hamilton et al. [19] present a detailed conceptual framework built on wildfire social science literature and a simplification of models of behavioral adaptation to climate change, but make no attempt to estimate, parameterize, or test the model. Olsen et al. [29] model relationships among homeowners' perceived wildfire risk components and biophysical data, finding that wildfire risk perceptions correlate with modeled fire behavior and that perceived risk relates to self-reported mitigation behaviors. Martin et al. [23] model the number of self-reported risk reduction actions taken with a mediating effects model, finding that subjective knowledge and locus of responsibility influence risk reductions via risk perceptions, suggesting joint determination of risk perceptions with risk reduction decisions. Champ et al. [30] model self-reported mitigation activity as a function of risk perceptions and other variables, jointly with risk perceptions as a function of other variables, using a simultaneous bivariate ordered probit. They find similar determinants (i.e., accessing the Colorado Springs Fire Department's FireWise website) for both perceived risk and reported mitigation, thereby demonstrating that higher perceived risk alone does not lead to higher mitigation levels. Somewhat similarly, Nagle [31] demonstrates the endogeneity (Endogeneity refers to the situation in which an explanatory variable in a model is correlated with the error term of that model. This can lead to biased estimates and incorrect inference. For example, Nagle [31] demonstrate that "concern" is correlated with the error term in the model of self-reported mitigation activities) of concern about wildfire on self-reported mitigation activities with an instrumental variable approach, using modeled burn probabilities [32] as an instrument for concern, measured on a 5-point Likert scale from very unconcerned to very concerned. Nagle argues that this endogeneity may bias estimates of perceived risk in models of mitigation behavior, thereby potentially explaining previous results that failed to find a significant effect. Finally, Paveglio et al. [33] estimate risk as a function of burn probability, self-reported fuel reduction activities, and sensitivity to potential financial losses. They find that self-reported parcel-level characteristics better explain the variability in wildfire exposure, sensitivity, and overall risk from wildfire in their sample than do variables on sociodemographics and risk perceptions. In particular, they note that residents' wildfire risk perceptions, even when separated into probability of fire and conditional expectations of consequences, do not correlate well with exposure (defined as the probabilistic likelihood that a given disturbance impacts people or their resources), sensitivity (defined as potential financial losses through structure and land damage), or risk. However, they do find that perceived likelihood of wildfire burning on private lands in their county (defined as "perceived property risk") is positively associated with self-reported mitigation efforts. 
Despite the knowledge garnered from this body of research, to date this literature does not capture an important potential feedback between mitigation and risk perceptions. Specifically, none of these studies investigate the potential dual-directional relationship between mitigation activities and perceived risk to one's home. The related literature tends to rely on reduced-form models that neglect the fact that presumably residents conduct fuel mitigation both because they believe they are at risk from wildfire and because they believe mitigation affects their risk from wildfire.

In addition, the body of literature to date tends to focus on self-report mitigation behaviors. This is potentially problematic as research in other contexts has found a "social desirability bias" from using self-reported data for which socially-desirable responses are clear (e.g., [34,35]). Such bias may exist here if respondents consider engaging in activities that reduce society's overall risk from wildfire-or the risk of wildfire to their neighbors-as socially desirable, a likely scenario. In the wildfire context, Meldrum et al. [36] found significant divergences between professional and residents' assessments of parcel-level, wildfire risk-related conditions, including those over which a resident has control such as those relating the structural hardening and defensible space. In addition to self-report biases, such divergences could relate to differing interpretations between survey respondents and professional assessors of what effective defensible space looks like, for example, or more generally to respondents lacking the requisite expertise for evaluating the specific characteristics measured. For a telling example, Meldrum et al. report that many respondents assessed their driveway width differently from the professional, suggesting a difference in how a trained observer judges distance versus the general public.

Here, we address these gaps in the literature by estimating a system of equations that allows not only for risk perceptions to affect risk mitigation behaviors but also for the parcel-level conditions created by these mitigation behaviors to simultaneously affect risk perceptions. Thus, our analysis tests the simplified conceptual model presented in Figure 1, in which wildfire hazards influence risk perceptions, risk perceptions influence mitigation actions, and mitigation actions influence risk perception. Based on past research results, we expect that residents who perceive higher wildfire risks will be more likely to conduct wildfire risk mitigation on their properties. We also expect that having conducted wildfire risk mitigation leads residents to perceive their wildfire risk as lower. Critically, we expect that analyses that do not account for both effects simultaneously, such as correlation statistics or simple regressions that ignore potential endogeneity, can generate misleading results.

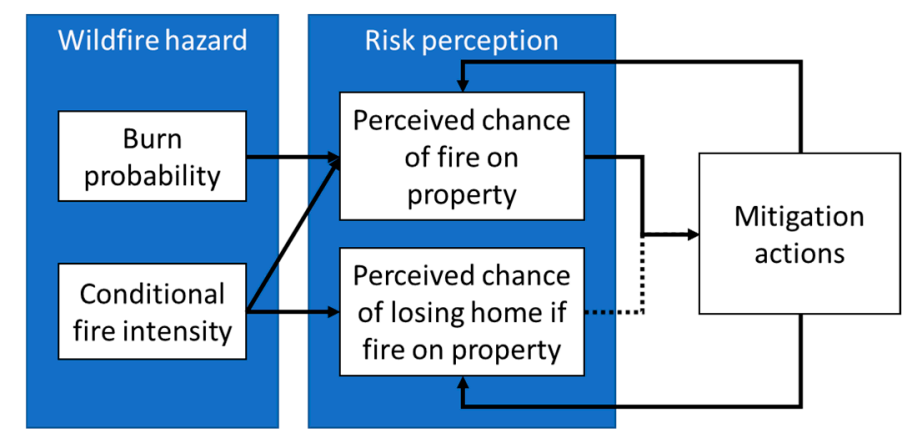

Figure 1. Conceptual model of relationship between wildfire hazard, risk perceptions, and mitigation actions. Dotted line depict relationship expected but not found in empirical results below.

Because of the infeasibility of directly and consistently observing mitigation actions across a large set of private properties, and our concerns in relying solely on self-reported data on mitigation actions described above, we are unable to truly measure risk mitigation decisions. Instead, we rely on measures of parcel-level characteristics that represent items that are associated with wildfire risk to a home and over which residents can exert direct control: such measures thereby represent the outcomes of probable mitigation actions. As discussed below, results suggest that these conditions do indeed reflect mitigation actions taken on the property. Overall, our results suggest direct feedback between 
risk perceptions and wildfire risk-related parcel characteristics, implying that proper inference requires consideration of interactions between the two rather than simply considering correlations or simple reduced-form models.

\section{Data Sources}

Our analysis leverages a uniquely rich dataset of parcel-level rapid assessments and household survey data from 2006 residential parcels concentrated in 85 communities within six western Colorado counties (Archuleta, Delta, La Plata, Montezuma, Ouray, and San Miguel). The six-county region is growing rapidly, with a $157 \%$ increase in population from 1970 to 2017 , versus $59.8 \%$ nationwide, and a $37 \%$ increase in residential area from 2000 to 2010 , versus $12 \%$ nationwide. Statistics vary widely across the six counties, but generally regional employment in mining, agriculture, and tourism-related industries is significantly higher than national averages $(4.1 \%$ vs. $0.6 \%$; $4.7 \%$ vs. $1.3 \%$; and $28.3 \%$ vs. $15.3 \%$ ). Likewise, per capita income ranges from $\$ 38,375$ to $\$ 78,956$ by county, with a regional average $(\$ 48,464)$ below the US national average $(\$ 52,880)$, but with unemployment rates for four of the six counties (average of 3.6\%; ranging from 3.0\% to $4.7 \%$ ) below the national average (3.9\%). According to the USDA Forest Service [32], this six-county region has an average annual wildfire burn probability of $0.15 \%$ (ranging from 0 to $0.62 \%$ ), compared to the national US average of $0.25 \%$ (ranging from 0 to $11.56 \%$ ). However, the same dataset estimates that most likely conditional flame intensities for this six-county region would be significantly higher than the national average. Across the region, $20.5 \%$ of all homes are estimated as residing in the wildland-urban interface, higher than the western-US average of $7.0 \%$, although this ranges from $3.2 \%$ to $66.5 \%$ by county. Consistently across the six counties, approximately one-third of these WUI homes are second homes, compared to a western-US average of $15 \%$. All statistics above are generated from publicly available, federal data sources [37].

This region has been the focus of an on-going effort by the WiRē Team (short for Wildfire Research Team) to understand and support the mitigation of wildfire risk on private residential property through partnerships between research and the regional nongovernmental organizations of West Region Wildfire Council (WRWC) and Firewise of Southwest Colorado (FSC; now known as Wildfire Adapted Partnership). Both WRWC and FSC offer a combination of education, community planning support, and funding assistance for homeowner wildfire risk mitigation efforts in multi-county regions in western Colorado. While both organizations have been nationally recognized for their leadership in supporting wildfire preparedness, prevention, and mitigation, similar programs exist at communityto regional-levels across much of the WUI in the United States. The WiRē approach involves collecting parcel-level rapid assessment data and pairing these data with responses to surveys of the residents of these same properties, to inform and support community-specific wildfire education and mitigation outreach. Such information is useful for practitioners in tailoring programs appropriately and potentially increasing homeowner engagement with these programs. WRWC and FSC collect and maintain ownership of the rapid assessment and household survey data collected through this WiRe approach; data were subsequently shared with the WiRe Team to support research investigations such as the present study.

\subsection{Parcel-Level Conditions: WiRē Rapid Assessment}

We represent parcel-level conditions with the results of the WiRē Rapid Wildfire Risk Assessment ("rapid assessment") tool. This rapid assessment tool, which was developed iteratively by WRWC in collaboration with the US Bureau of Land Management, is emblematic of a class of assessment product that is currently experiencing rapid uptake among wildfire mitigation and suppression practitioners around the United States to assist with understanding parcel-level conditions associated with wildfire risk [38]. Reflecting its intended purposes of understanding and communicating parcel-level risk, this tool assesses both the probability that a wildfire in the area would burn on that property and the potential consequences to that property if that happens. 
Based on the fire science of the HIZ concept, the rapid assessment is comprised of eleven categories that are grouped into those beyond the control of a homeowner and associated with the underlying hazard (distance from home to dangerous topography, slope of the parcel, and the extent of background fuels on properties surrounding the parcel in question); key structural characteristics (roofing material, siding material, the existence and materials of decks and fencing); combustibles around the home (vegetation and other combustibles); as well as conditions related to the accessibility of the home to fire responders and evacuation potential (address visibility, ingress/egress, and driveway clearance). While the ignitability of a home may be influenced by many additional factors, these 11 categories are weighted based on their relative contribution to overall wildfire risk. The weighted sum thereby provides a snapshot of a parcel's conditions related to its wildfire risk.

Rapid assessments are conducted from the roadside by a trained wildfire mitigation professional and take approximately $60 \mathrm{~s}$, with the intention of providing a low-cost method to understand a community's general wildfire risk landscape. When a census of residential parcels in a fire-prone community is conducted by local experts, these 11 attributes provide a relative risk rating score and a general assessment of a community's wildfire risk landscape. This score can be categorized into an overall wildfire risk rating that assigns an adjective to each property based on its sum (Low, Medium, High, Very High, Extreme). Here, we focus on the sum of the five assessed attributes that provide a gross snapshot of parcel-level conditions within the HIZ that are associated with the vulnerability of a home to wildfire and can be affected by residents' mitigation behaviors (RA_HIZ): roofing material, siding material, the existence and materials of decks and fencing, vegetation near the home, and other combustibles near the home. We then standardize the RA_HIZ scores to approximately match the scale of other variables used in the model. Higher scores are associated with higher levels of home vulnerability; similarly, higher scores are associated with conditions that suggest that less mitigation has been performed by either the current resident or a previous occupant of the property, and thus present when the current resident decided to move into the location. Table 1 provides descriptive statistics.

Table 1. Descriptive statistics for wildfire risk-related assessments and survey responses related to resident characteristics and perceptions of wildfire risk.

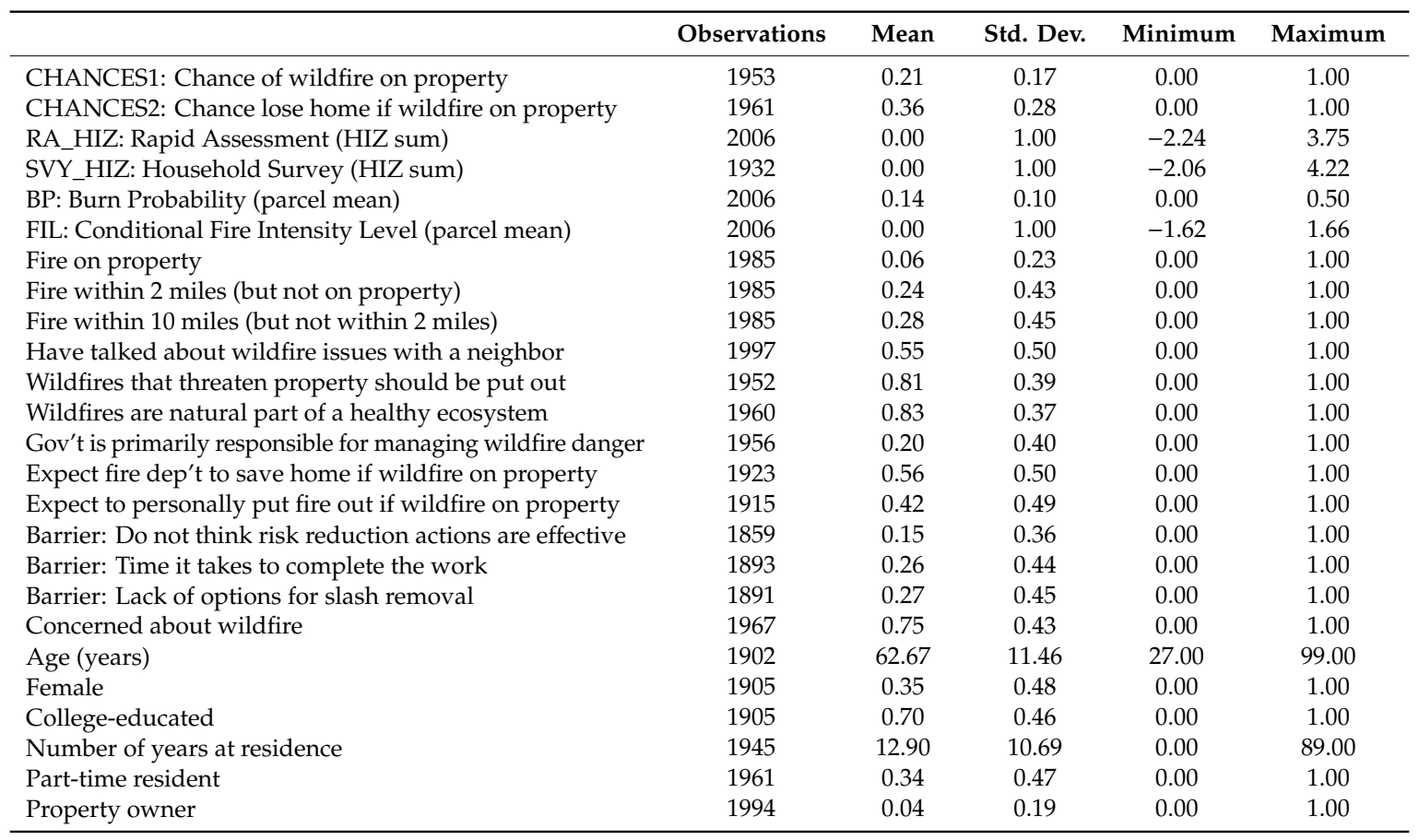




\subsection{WiRē Household Survey}

Household survey data reported here were collected by the regional wildfire mitigation organizations WRWC and FSC for all residential properties within selected communities. The surveys elicit responses on many dimensions of residents' relationships with wildfire, as well as personal and property characteristics. Response rates, adjusted for non-deliverable surveys, vary from approximately $30 \%$ in the selected communities in Archuleta County to $62 \%$ in the selected communities in Ouray County. Survey data are matched to 2006 assessed parcels, for a combined effective response rate of $33 \%$. Technical reports provide further information and full results [39-44].

Here, we consider variables on risk perceptions, fire experience, expectations and attitudes about wildfire risk, and perceived barriers to conducting risk mitigation on one's property. In particular, we focus on measures of the perceived chance of a wildfire on one's property in the next year (CHANCES1) and the perceived chance that one's home would be damaged or destroyed if that occurred (CHANCES2). We also consider a self-assessed SVY_HIZ rating constructed from survey questions inquiring about the survey respondents' own consideration of the same variables captured by RA_HIZ and aggregated using the same weights thereof. Key variables, as well as basic demographics for the sample, are described in Table 1.

\subsection{Hazard: Burn Probability and Fire Intensity}

To represent the wildfire hazard presented by biophysical conditions, we consider the Burn Probability (BP) and Conditional Fire Intensity Level (FIL) outputs published for the entire conterminous United States at a $270 \mathrm{~m}$ grid spatial resolution by Short et al. [32]. These data depict the results of the geospatial Fire Simulation (FSim) system [45], which estimates probabilistic components of wildfire risk based on modules for weather generation, wildfire occurrence, fire growth, and fire suppression. While these simulated results are intended to support national strategic planning efforts and are not necessarily applicable for supporting fire and land management planning on smaller areas, they provide useful measures for controlling for residents' perceptions of landscape level conditions and the associated wildfire hazards to their property. The Burn Probability (BP) layer indicates the tendency of any given pixel to burn, given static landscape conditions from 2012, contemporary weather and ignition patterns, and fire management policies (including considerable fire prevention and suppression efforts). The Conditional Fire Intensity Level layers depict the proportions of simulated fires in each flame length class (FIL1 $=<2$ feet $(\mathrm{ft}) ;$ FIL2 $=2<4 \mathrm{ft}$.; FIL3 $=4<6 \mathrm{ft}$.; FIL4 $=6<8 \mathrm{ft}$.; FIL5 $=8<$ $12 \mathrm{ft} . ;$ FIL6 $=12+\mathrm{ft}$ ) for all simulated fires that burned within a particular cell. We calculate the most common modeled Conditional Fire Intensity Level for each cell and use that as our Fire Intensity Level (FIL) measure. To downscale fire hazard statistics to the parcel level, we intersect the BP and FIL layers with parcel footprint data acquired from the County Assessor's office for each county with the study area and joined to rapid assessment data and calculate zonal statistics for each parcel for raster data. We report parcel means throughout the paper; other reasonable statistics (i.e., median, mode) do not meaningfully change the reported results.

\section{Methods}

\subsection{Correlations between Key Variables}

Table 2 presents correlation coefficients between key variables to demonstrate the relationships that are observed if potential complexities are ignored; we emphasize that subsequent analyses are strongly preferred over the results in Table 2. The fire hazard ratings, BP and FIL, are correlated with each other $(\rho=0.57)$, and the HIZ-related parcel conditions assessed either by the professional (RA_HIZ) or by survey respondents (SVY_HIZ) are also correlated with each other $(\rho=0.52)$. Neither fire hazard variable is correlated with the RA_HIZ score, suggesting that there exists no overall strong relationship between the exposure of a house in this study area to the wildfire hazard and how well-protected is that home's HIZ. CHANCES1, the perceived chance of a wildfire occurring on 
one's property, is weakly correlated with the hazard variables but not correlated with the parcel-level conditions, which is consistent with respondents' having a relatively sophisticated understanding of the level of wildfire hazard faced by their property but not considering that HIZ characteristics, such as defensible space, could also influence the probability of wildfire spreading onto their property. In contrast, CHANCES2, the perceived probability of damage to one's home conditional on wildfire occurring on their property, is not correlated with the wildfire hazard, which is consistent with the conditional probability phrasing of the measure. However, CHANCES1 and CHANCES2 are also correlated $(\rho=0.35)$, which nonetheless suggests that the two risk perception variables might be jointly determined. Further, both RA_HIZ and SVY_HIZ are positively correlated with CHANCES2, which could make intuitive sense in that respondents with more vulnerable parcel conditions also perceive a higher probability of negative consequences from a fire on their property.

Table 2. Correlation coefficients among assessment and survey variables $(n=1893)$; note that results from more sophisticated analyses are strongly preferred over these.

\begin{tabular}{lcccccc}
\hline & BP & FIL & RA_HIZ & SVY_HIZ & CHANCES1 & CHANCES2 \\
\hline BP: Burn Probability & 1 & 0.57 & 0.08 & -0.15 & 0.12 & 0.01 \\
FIL: Conditional Fire Intensity Level & 0.57 & 1 & 0.07 & -0.06 & 0.14 & 0.06 \\
RA_HIZ: Rapid Assessment (HIZ sum) & 0.08 & 0.07 & 1 & 0.52 & -0.04 & 0.19 \\
SVY_HIZ: Household Survey (HIZ sum) & -0.15 & -0.06 & 0.52 & 1 & 0.00 & 0.27 \\
CHANCES1: Chance of wildfire on property & 0.12 & 0.14 & -0.04 & 0.00 & 1 & 0.35 \\
CHANCES2: Chance lose home if wildfire & 0.01 & 0.06 & 0.19 & 0.27 & 0.35 & 1 \\
\hline
\end{tabular}

\subsection{Simultaneous Model}

However, while simple correlations between measures describe how the two are related within the population of considered parcels, potential interactions between the measures mean that inference based on these relationships might be misleading. Thus, we estimate a simultaneous equations model to better understand the relationship among residents' perceptions of their wildfire risk, their parcel-level conditions, and their wildfire hazard as estimated by landscape-level fire behavior modeling, recognizing the potential for interactions among the three to confound inference based on simple correlations. Specifically, we jointly estimate the following system of equations which accounts for the endogeneity of the perceived chance of wildfire on one's property (CHANCES1), the perceived chance of home damage in the event of wildfire on one's property (CHANCES2), and the HIZ-related characteristics captured by the parcel-level Rapid Assessment (RA_HIZ) as follows. This simultaneous model is built to estimate and test the simplified conceptual model shown graphically in Figure 1 above. As with all models, our model is a simplification and does not include all possible influences; rather, it is constructed primarily to investigate the relationships between wildfire risk perceptions and mitigation actions.

$$
\left(\begin{array}{c}
\text { CHANCES1 }=\mathrm{f}\left(\mathrm{RA}_{\mathrm{HIZ}}, \mathrm{BP}, \mathrm{FIL}, \mathrm{X}, \epsilon_{1}\right) \\
\text { CHANCES2 }=\mathrm{f}\left(\mathrm{RA}_{\mathrm{HIZ}}, \mathrm{BP}, \mathrm{FIL}, \mathrm{Y}, \epsilon_{2}\right) \\
\mathrm{RA}_{\mathrm{HIZ}}=\mathrm{f}\left(\mathrm{CHANCES1}, \mathrm{CHANCES}, \mathrm{BP}, \mathrm{FIL}, \mathrm{Z}, \epsilon_{3}\right)
\end{array}\right)
$$

Previous models $[29,30]$ have introduced the role of perceived risk in the model of mitigation while allowing for the correlation of the error term between this model of mitigation and the model predicting perceived risk. Our model closes the loop by further adding the potential feedback through which mitigation work that has been conducted on the property has a potential direct influence on the risk perceptions of that property's resident. In other words, the system of equations reflects the possibility that residents' perceptions of the likelihood that wildfire might reach their property (CHANCES1) and that that wildfire would cause damage if so (CHANCES2) are both influenced by conditions of that property, as measured by RA_HIZ. At the same time, the system also recognizes that RA_HIZ measures conditions of the property that would reflect risk mitigation actions taken 
by property residents, and residents' decisions regarding these actions are potentially influenced by those residents' perceptions of wildfire risk, as measured by CHANCES1 and CHANCES2. Each equation also includes other sets of variables, X, Y, and Z, which contain survey data selected to support instrumental variable estimation and based on previous results on factors related to risk perceptions, mitigation behaviors, or both, and independent but identically distributed error terms $\epsilon_{1}, \epsilon_{2}$, and $\epsilon_{3}$. We estimate all models in STATA: individual (reduced form) equations are tested for endogeneity and valid instruments using the ivregress and associated postestimation commands; final estimation of the full system of three equations is conducted with the reg3 command for three-stage least squares estimation for systems of simultaneous equations [46].

\subsection{Self-Report Versus Assessed Data}

The model described above includes RA_HIZ as its measure of parcel-level characteristics because of the potential bias in self-reporting of conditions affected by mitigation behavior (SVY_HIZ). To assess the likelihood of such problems from bias, we first note that while RA_HIZ and SVY_HIZ are correlated with each other $(\rho=0.52)$, that correlation is far from perfect, signifying that the two measures differ. Indeed, we calculate the difference between the standardized SVY_HIZ and RA_HIZ scores and note that this difference is nearly normally distributed with mean -0.004 but standard deviation of 0.97 , and a range from -4.50 to 4.65 . This implies that the full spectrum of possible differences is manifest in the data. For further insight, we build on Meldrum et al.'s [36] correlational analysis that attempted to explain systematic differences between the household survey's reported risk assessment ratings and those from the professional assessment, for a small subset $(n=256)$ of the data analyzed here. Here, we estimate an ordinary regression that allows for multivariate influence upon a dependent variable based on the difference between our professionally assessed and resident-assessed HIZ-condition variables. We report two models: the first a reduced model that includes only CHANCES1 and CHANCES2, and the second a richer model with potentially influential survey data but a smaller $n$ due to item non-response. Although both models are overall quite weak for explaining the difference (R-squared for the full model $=0.05$ ), results in Table 3 show the critical result of a systematic relationship between CHANCES2 and the difference between SVY_HIZ and RA_HIZ. That is, we find that respondents who report a higher chance of losing their home if a fire burns on their property are more likely to rate the HIZ-related vulnerability on their property significantly higher than the professional rates that same property. Further, having talked with neighbors about wildfire issues, the length of tenure at the property, and one's income level are all systematically associated with the difference between the resident's and the professional's ratings of the HIZ conditions. Although multiple factors could help explain this difference, the findings for talking with neighbors and CHANCES2 are consistent with what would be predicted if the social desirability bias existed in the SVY_HIZ. Further, the presence of any systematic relationships explaining the difference between survey and assessed variables suggests a risk of systematic bias from relying on the self-reported data, assuming the professional data are valid. Accordingly, we believe sufficient evidence exists to prefer the use of RA_HIZ in the system of equations for conditions associated with mitigation and risk perceptions. 
Table 3. Regression models of difference (=RA_HIZ-SVY_HIZ) between professional- and self-assessed HIZ conditions; higher values signify residents underestimating the HIZ-related vulnerability compared to the professional.

\begin{tabular}{|c|c|c|c|c|}
\hline \multirow{2}{*}{$\begin{array}{c}\text { Regression; Dependent Variable = } \\
\text { (SVY_HIZ-RA_HIZ) }\end{array}$} & \multicolumn{2}{|c|}{ Equation (1) } & \multicolumn{2}{|c|}{ Equation (2) } \\
\hline & Coef & StdErr & Coef & StdErr \\
\hline CHANCES1: Probability of fire on property & 0.09 & 0.14 & 0.07 & 0.16 \\
\hline CHANCES2: Chance lose home if fire on property & $0.29 * * *$ & 0.09 & $0.26^{* *}$ & 0.10 \\
\hline Received information about wildfire from local fire dep't & - & & 0.00 & 0.05 \\
\hline Received information about wildfire from media & - & & 0.07 & 0.05 \\
\hline Wildfire has been on property & - & & 0.10 & 0.11 \\
\hline Wildfire has been within $0-2$ miles of property & - & & 0.03 & 0.06 \\
\hline Know someone who has evacuated due to wildfire & - & & -0.07 & 0.05 \\
\hline Have talked about wildfire issues with a neighbor & - & & $-0.33^{* * *}$ & 0.05 \\
\hline Tenure at property (10 years) & - & & $0.06^{* *}$ & 0.02 \\
\hline Female & - & & -0.04 & 0.05 \\
\hline Attended college & - & & -0.04 & 0.06 \\
\hline $\ln$ (Income) & - & & $-0.11^{* * *}$ & 0.03 \\
\hline Constant & $-0.11^{* *}$ & 0.02 & $1.21^{* * *}$ & 0.37 \\
\hline $\mathrm{N}$ & \multicolumn{2}{|c|}{1862} & \multicolumn{2}{|c|}{1457} \\
\hline R-squared & \multicolumn{2}{|c|}{0.01} & \multicolumn{2}{|c|}{0.05} \\
\hline
\end{tabular}

coef $=$ coefficient; stdErr $=$ standard error; ${ }^{* *} p<0.01,{ }^{* * *} p<0.001$.

\section{Result}

Table 4 reports our main results, from the simultaneous model of CHANCES1, CHANCES2, and RA_HIZ. The top panel depicts the preferred results of the simultaneous model. For comparison, the bottom panel depicts individual equations estimated by ordinary least squares (OLS); these do not account for the endogeneity of risk perceptions and mitigation decisions and thus may be biased.

Table 4. Estimated coefficients of separate and simultaneous regression models of survey respondents' self-reported perception of likelihood of wildfire on their property (CHANCES1), likelihood of damage to their home if that occurs (CHANCES2), and the professionally assessed HIZ conditions (RA_HIZ). For all outcome variables, higher values correspond to higher risk. $(n=1677)$.

\begin{tabular}{|c|c|c|c|c|c|c|}
\hline \multirow{3}{*}{ Dependent Variable: } & \multicolumn{2}{|c|}{ Equation (1) } & \multicolumn{2}{|c|}{ Equation (2) } & \multicolumn{2}{|c|}{ Equation (3) } \\
\hline & \multicolumn{2}{|c|}{ CHANCES1 } & \multicolumn{2}{|c|}{ CHANCES2 } & \multicolumn{2}{|c|}{ RA_HIZ } \\
\hline & Coef & StdErr & Coef & StdErr & Coef & StdErr \\
\hline \multicolumn{7}{|c|}{ PANEL 1: Simultaneous Model (Accounting for Endogeneity) } \\
\hline CHANCES1: Probability of fire on property & [Dep. & Jar.] & - & & $-3.26^{* * *}$ & 0.83 \\
\hline CHANCES2: Chance lose home if fire on property & - & & [Dep. & Jar.] & 0.15 & 0.36 \\
\hline BP: Burn Probability & $0.86^{* * *}$ & 0.23 & $1.31 *$ & 0.51 & -0.90 & 1.10 \\
\hline $\mathrm{BP}^{\wedge} 2$ & $-2.52 * * *$ & 0.61 & $-4.71 * * *$ & 1.34 & $5.39 *$ & 2.55 \\
\hline FIL: Conditional Fire Intensity Level & 0.01 & 0.01 & -0.01 & 0.02 & $0.09 *$ & 0.04 \\
\hline FIL^2 & $-0.01 *$ & 0.01 & -0.02 & 0.02 & $0.08 *$ & 0.03 \\
\hline Wildfire has been on property & $0.12^{* * *}$ & 0.03 & 0.05 & 0.06 & - & \\
\hline Wildfire has been within $0-2$ miles of property & $0.07^{* * *}$ & 0.02 & 0.03 & 0.03 & - & \\
\hline Wildfires are natural part of a healthy ecosystem & - & & 0.00 & 0.02 & - & \\
\hline Gov't is primarily responsible for managing wildfire danger & $-0.04^{* *}$ & 0.01 & $-0.09 * *$ & 0.03 & 0.13 & 0.07 \\
\hline Expect fire dep't to save home if wildfire on property & $-0.03 * *$ & 0.01 & $-0.17^{* * *}$ & 0.02 & - & \\
\hline Expect to personally put fire out if wildfire on property & - & & - & & $-0.33^{* * *}$ & 0.07 \\
\hline Barrier: Do not think risk reduction actions are effective & - & & - & & $0.16^{* *}$ & 0.06 \\
\hline Barrier: Time it takes to complete the work & - & & - & & $0.16^{* *}$ & 0.05 \\
\hline Barrier: Lack of options for slash removal & - & & - & & $0.17^{* * *}$ & 0.05 \\
\hline Constant & $0.13^{* * *}$ & 0.03 & $0.35^{* * *}$ & 0.06 & $0.53^{* *}$ & 0.21 \\
\hline
\end{tabular}


Table 4. Cont.

\begin{tabular}{|c|c|c|c|c|c|c|}
\hline \multirow{3}{*}{ Dependent Variable: } & \multicolumn{2}{|c|}{ Equation (1) } & \multicolumn{2}{|c|}{ Equation (2) } & \multicolumn{2}{|c|}{ Equation (3) } \\
\hline & \multicolumn{2}{|c|}{ CHANCES1 } & \multicolumn{2}{|c|}{ CHANCES2 } & \multicolumn{2}{|c|}{ RA_HIZ } \\
\hline & Coef & StdErr & Coef & StdErr & Coef & StdErr \\
\hline \multicolumn{7}{|c|}{ PANEL 2: Separate OLS Models (with Endogeneity Problems) } \\
\hline CHANCES1: Probability of fire on property & [Dep. & Tar.] & - & & $-0.69 * * *$ & 0.15 \\
\hline CHANCES2: Chance lose home if fire on property & 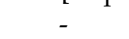 & & [Dep. & Jar.] & $0.63^{* * *}$ & 0.09 \\
\hline BP: Burn Probability & $0.49 * *$ & 0.16 & 0.27 & 0.25 & $-2.20 *$ & 0.92 \\
\hline $\mathrm{BP}^{\wedge} 2$ & $-1.14^{* *}$ & 0.37 & -0.87 & 0.59 & $8.10^{* * *}$ & 2.17 \\
\hline FIL: Conditional Fire Intensity Level & $0.02 * *$ & 0.01 & 0.01 & 0.01 & 0.05 & 0.03 \\
\hline FIL^2 & 0.00 & 0.00 & $0.02 *$ & 0.01 & $0.07 * *$ & 0.03 \\
\hline Wildfire has been on property & $0.06^{* * *}$ & 0.02 & $-0.09 * *$ & 0.03 & - & \\
\hline Wildfire has been within $0-2$ miles of property & $0.04 * * *$ & 0.01 & $-0.05^{* *}$ & 0.02 & - & \\
\hline Wildfires are natural part of a healthy ecosystem & - & & 0.00 & 0.02 & & \\
\hline Gov't is primarily responsible for managing wildfire danger & -0.01 & 0.01 & -0.01 & 0.02 & $0.18^{* *}$ & 0.06 \\
\hline Expect fire dep't to save home if wildfire on property & $-0.03 * * *$ & 0.01 & $-0.17^{* * *}$ & 0.01 & - & \\
\hline Expect to personally put fire out if wildfire on property & - & & - & & $-0.16^{* *}$ & 0.05 \\
\hline Barrier: Do not think risk reduction actions are effective & - & & - & & $0.15^{*}$ & 0.07 \\
\hline Barrier: Time it takes to complete the work & - & & - & & -0.03 & 0.06 \\
\hline Barrier: Lack of options for slash removal & - & & - & & $0.13 *$ & 0.06 \\
\hline Constant & $0.16^{* * *}$ & 0.02 & $0.42^{* * *}$ & 0.03 & -0.08 & 0.10 \\
\hline
\end{tabular}

coef $=$ coefficient; stdErr $=$ standard error; ${ }^{*} p<0.05,{ }^{* *} p<0.01,{ }^{* * *} p<0.001$.

Focusing first on the estimated coefficients from the preferred simultaneous model, we see that both risk-related perceptions (CHANCES1: the chance of wildfire on one's property, which corresponds to an estimation of the hazard, and CHANCES2: the chance of negative consequences if that happens, which corresponds to an estimation of the vulnerability) increase with a higher RA_HIZ score, which corresponds to more vulnerable HIZ conditions and is consistent with less mitigation. This makes intuitive sense, consistent with our expectations, and demonstrates that residents consider parcel-level characteristics when assessing their wildfire risk. For intuition regarding the parameter estimates, we note that a 10\% increase in CHANCES1 is associated with a 25-point decrease in the (non-transformed) Rapid Assessment score, which approximately corresponds to the difference between storing firewood 10 feet versus 30 feet from the structure, or else between having non-combustible siding versus heavy $\log$ siding. Further, the positive and significant coefficients on simulated burn probability estimates for CHANCES1 and CHANCES2 demonstrate that risk perceptions are further influenced by the conditions that underly the sophisticated FSim modeling, and in a manner generally consistent with the results of that modeling, although the negative coefficient on the second-order term shows that this effect diminishes and even reverses at higher estimated burn probabilities. However, contrary to our expectations, respondents' risk perceptions are not systematically associated with FIL, which measures the intensity of a fire if it occurs and therefore is expected to correspond to the amount and likelihood of damage to any structures in the presence of that fire. Experience with nearby fires influences CHANCES1 but is irrelevant for CHANCES2 in the simultaneous model. Interestingly, social interactions about fire are associated with higher perceptions of both aspects of risk, whereas expectations regarding government and firefighting resources for protecting one's property are both associated with lower perceptions of both aspects of risk.

For the measure of HIZ conditions (RA_HIZ), the negative coefficient on CHANCES1 implies that higher expectations of fire occurring on one's property lead to less vulnerable properties (and thus is consistent with greater mitigation effort), but the lack of significance on CHANCES2 shows no such effect for the perceived vulnerability of one's property, conditional on a given CHANCES1. Expectations about being able to personally extinguish a wildfire are associated with lower HIZ vulnerability, which is consistent with respondents with higher levels of perceived self-efficacy conducting more mitigation. 
In contrast, reporting any of numerous possible barriers to conducting mitigation, including perceiving it as ineffective, limitations on one's time, and a lack of known options for removing slash or waste material after conducting fuels reduction work, is strongly associated with having more vulnerable HIZ conditions. Importantly, this is to be expected if the conditions measured by RA_HIZ serve as a useful measure of risk mitigation actions on and around the home; it is difficult to explain if the observed conditions were not a useful proxy of actions.

Comparison against the bottom panel shows a general robustness of most relationships in the biased separate models, with the important exceptions of the coefficients on RA_HIZ being estimated as insignificant and essentially zero in the biased model for CHANCES1 and the coefficient on CHANCES2 being estimated as strongly significant and substantial in the biased model for RA_HIZ. This biased result inaccurately suggests that having more vulnerable HIZ conditions does not influence one's perception of the chance of fire on their property and that perceiving a higher conditional vulnerability (CHANCES2) leads to higher assessed vulnerability conditions. The latter biased result demonstrates an important benefit of the simultaneous model: simultaneous modeling separates the influence of one endogenous variable on another from the inverse, whereas the endogeneity-biased separate models can only demonstrate correlation between the variables.

Results for the system of equations are functionally identical to separate instrumental variables regressions using excluded variables from each equation in the system as the instruments for that respective reduced-form equation (not shown). Although simultaneously modeled results are preferred due to the sequentially iterative estimation of all instruments and outcome variables, as well as increased statistical efficiency, estimation of separate instrumental variable models allows for diagnostics of the statistical performance of instruments. Interestingly, in our search for variables to include as instruments for mitigation behavior in the risk perception models, we found most potential candidates to be directly correlated with risk perceptions and thus not valid instruments for mitigation in the risk perception equation; this was less frequently an issue in the search for valid instruments for risk perceptions in the mitigation equation. Statistical testing of the separate models verifies the joint determination of CHANCES1, CHANCES2, and RA_HIZ, and that the excluded variables serve as valid (though weak) instruments. Specifically, the C (difference-in-Sargan) statistic tests the endogeneity of RA_HIZ in CHANCES1 and CHANCES2 models, and of CHANCES1 and CHANCES2 in the RA_HIZ model; in all cases the null of exogeneity is rejected at $p<0.01$ or stricter. Partial R-squared values for the first-stage regressions, which pertain exclusively to the excluded variables, are all low, between 0.021 and 0.084 , but first-stage models are all significant per F tests at $p<0.001$ (F-statistics between 9.98 and 26.42) and with R-squared values between 0.082 and 0.192 . All three models also fail to reject Hansen's J statistic chi-squared test, at $p=0.29, p=0.20$, and $p=0.27$, respectively, thereby demonstrating no evidence of invalid instruments due to overidentification restrictions. Reported main results (i.e., those pertaining to CHANCES1, CHANCES2, RA_HIZ, and BP and FIL) are also robust to testing of various alternative combinations of potential covariates and instruments available in the survey data, including adding in demographic variables that were omitted from the main model due to the significant item non-response. Further, because past work demonstrates spatial clustering of many variables from the rapid assessments and household surveys among neighbors [47] and within communities [48], we investigate the robustness of assuming independent and identically distributed errors in our model. Specifically, we estimate a Cliff-Ord spatial autoregressive model with endogenous covariates for each dependent variable, using the STATA command spivreg [49]. Despite the estimate significance of both the spatial lag and spatial error terms using either an inverse-distance or a contiguity spatial weights matrix, reported results are robust between spatial and non-spatial models. Results, which are estimated only for the separate models rather than the more-efficient simultaneous model, are not shown for brevity but are available from the authors. 
Finally, despite our concerns regarding using self-reported parcel-level risk assessment data, we note that the reported results are the same in sign and significance when replicated using the self-reported mitigation score, as shown in Table 5. This result likely reflects the substantial correlation between the self-reported and professional assessed mitigation variables $(\rho=0.52)$ and supports inference based on similarly robust modeling reported elsewhere that has been conducted with self-report data. Indeed, the similarity of models with RA_HIZ (Table 4) and SVY_HIZ (Table 5) suggests that relative patterns in residents' thoughts about HIZ conditions reflect patterns in actual, externally observable HIZ conditions on the property, despite the demonstrated systematic differences between the survey and professional assessment evaluation of HIZ conditions. Because RA_HIZ measures conditions of a property whereas SVY_HIZ measures residents' thoughts about those conditions, this suggests-though it does not prove-that the HIZ conditions do indeed reflect mitigation actions, and not just conditions coincident with mitigation actions but determined by other processes. This is most strongly suggested by the third columns, which not only demonstrates a strong link from perceptions of the wildfire hazard to parcel level conditions but also does so in the opposite direction from the relationship between the two in the first column, which reflects the influence of the parcel-level conditions on the perception of the wildfire hazard. This is consistent with the simultaneous model in which parcel-level conditions affect risk perceptions, but risk perceptions also influence decisions about risk mitigation. However, we maintain in general the caution that the correlation between professionally assessed and self-reported parcel-level conditions is far from perfect, evidence suggests the potential for biased reporting is a real concern, and thus we continue to encourage validation of self-reported mitigation information where possible.

Table 5. Estimated coefficients of separate and simultaneous regression models of survey respondents' self-reported perception of likelihood of wildfire on their property (CHANCES1), likelihood of damage to their home if that occurs (CHANCES2), and the survey-generated estimation of mitigation (SVY_HIZ). For all outcome variables, higher values correspond to higher risk $(n=1643)$.

\begin{tabular}{|c|c|c|c|c|c|c|}
\hline & \multicolumn{2}{|c|}{ Equation (1) } & \multicolumn{2}{|c|}{ Equation (2) } & \multicolumn{2}{|c|}{ Equation (3) } \\
\hline & Coef & StdErr & Coef & StdErr & Coef & StdErr \\
\hline \multicolumn{7}{|c|}{ PANEL 1: Simultaneous Model (Accounting for Endogeneity) } \\
\hline CHANCES2: Chance lose home if fire on property & - & & [Dep. & Var.] & 1.16 & 0.69 \\
\hline SVY_HIZ: Household Survey (HIZ sum) & $0.17^{* * *}$ & 0.04 & $0.46^{* * *}$ & 0.07 & \multicolumn{2}{|c|}{ [Dep. Var.] } \\
\hline FIL: Conditional Fire Intensity Level & 0.01 & 0.01 & -0.02 & 0.02 & $0.17^{* *}$ & 0.06 \\
\hline FIL`2 & -0.01 & 0.01 & 0.01 & 0.01 & -0.02 & 0.05 \\
\hline Wildfire has been on property & $0.09 * * *$ & 0.03 & -0.03 & 0.05 & $0.58 *$ & 0.28 \\
\hline Wildfire has been within $0-2$ miles of property & $0.07^{* * *}$ & 0.02 & 0.03 & 0.03 & 0.23 & 0.17 \\
\hline Wildfire has been within $2-10$ miles of property & 0.03 & 0.02 & 0.01 & 0.03 & -0.10 & 0.11 \\
\hline Expect fire dep't to save home if wildfire on property & -0.02 & 0.01 & $-0.14 * * *$ & 0.02 & - & \\
\hline Expect to personally put fire out if wildfire on property & - & & - & & $-0.44^{* * *}$ & 0.11 \\
\hline Barrier: Do not think risk reduction actions are effective & - & & - & & $0.30 * *$ & 0.10 \\
\hline Barrier: Time it takes to complete the work & - & & - & & $0.26^{* * *}$ & 0.07 \\
\hline Constant & 0.03 & 0.04 & 0.08 & 0.08 & $1.43^{* * *}$ & 0.34 \\
\hline
\end{tabular}

coef $=$ coefficient; stdErr $=$ standard error; ${ }^{*} p<0.05,{ }^{* *} p<0.01,{ }^{* * *} p<0.001$. 
Table 5. Cont.

\begin{tabular}{|c|c|c|c|c|c|c|}
\hline & \multicolumn{2}{|c|}{ Equation (1) } & \multicolumn{2}{|c|}{ Equation (2) } & \multicolumn{2}{|c|}{ Equation (3) } \\
\hline & Coef & StdErr & Coef & StdErr & Coef & StdErr \\
\hline \multicolumn{7}{|c|}{ PANEL 2: Separate OLS Models (with Endogeneity Problems) } \\
\hline CHANCES1: Probability of fire on property & [Dep. & Tar.] & - & & $-0.52 * * *$ & 0.15 \\
\hline CHANCES2: Chance lose home if fire on property & 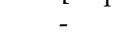 & & [Dep. & Jar.] & $0.88^{* * *}$ & 0.09 \\
\hline SVY_HIZ: Household Survey (HIZ sum) & 0.01 & 0.00 & $0.07^{* * *}$ & 0.01 & \multicolumn{2}{|c|}{ [Dep. Var.] } \\
\hline FIL: Conditional Fire Intensity Level & $0.02 * *$ & 0.01 & 0.01 & 0.01 & $0.07 *$ & 0.03 \\
\hline FIL`2 & 0.00 & 0.00 & $0.02 * *$ & 0.01 & 0.00 & 0.03 \\
\hline Wildfire has been on property & $0.07^{* * *}$ & 0.02 & $-0.09 * *$ & 0.03 & -0.05 & 0.11 \\
\hline Wildfire has been within $0-2$ miles of property & $0.04^{* * *}$ & 0.01 & $-0.05^{* *}$ & 0.02 & $-0.17^{* *}$ & 0.06 \\
\hline Wildfire has been within 2-10 miles of property & 0.00 & 0.01 & $-0.07 * * *$ & 0.02 & $-0.15^{* *}$ & 0.06 \\
\hline Expect fire dep't to save home if wildfire on property & $-0.03^{* * *}$ & 0.01 & $-0.16^{* * *}$ & 0.01 & - & \\
\hline Expect to personally put fire out if wildfire on property & - & & - & & $-0.15^{* *}$ & 0.05 \\
\hline Barrier: Do not think risk reduction actions are effective & - & & - & & $0.17^{* *}$ & 0.07 \\
\hline Barrier: Time it takes to complete the work & - & & - & & 0.03 & 0.05 \\
\hline Constant & $0.15^{* * *}$ & 0.02 & $0.37 * * *$ & 0.03 & $0.33^{* *}$ & 0.11 \\
\hline
\end{tabular}

\section{Discussion}

Our results demonstrate that residents within the study area tend to possess a fairly sophisticated understanding of the nuances between different aspects of wildfire risk to their homes. In general, risk perceptions are predicted as expected by the outputs of landscape-level fire modeling and the results of a parcel-level rapid assessment. The bulk of the evidence suggests that property characteristics provide a useful measure of mitigation actions that have been conducted on a property, and simultaneous equation modeling demonstrates the importance of capturing the joint determination of risk perceptions and parcel-level property characteristics. Combined, this suggests that residents' decisions to reduce their wildfire risk are not only influenced by their perceptions of wildfire risk, but also those actions subsequently influence those risk perceptions. This complexity is not a mere statistical footnote, but rather has a strong bearing on inference and implications.

Whereas a naïve, endogeneity-biased model suggests that the amount of mitigation conducted does not influence perceptions of the chance of wildfire on one's property, our simultaneous model suggests that residents conduct mitigation in the expectation that doing so will lower the chance that a fire burns on their property and that doing so will also reduce their home's vulnerability if that occurs. Appropriately controlling for the endogeneity of risk perceptions and parcel-level conditions clarifies and strengthens the intuitive results that the amount of mitigation conducted is also related to perceptions of how effective risk mitigation can be, expectations regarding one's own ability to extinguish a wildfire, and reported limitations regarding the removal of slash from one's property. However, it also leads to the nonintuitive result that we find no evidence of a feedback loop in which expectations about what would happen to one's home during a wildfire influence mitigation decisions (shown as a dotted line in the conceptual model of Figure 1). Of course, our measure of mitigation is only a coarse estimate of a small subset of possible mitigation actions; future research with a better lens on mitigation actions could uncover additional relationships not observed here. Likewise, evidence from across wildfire social science disciplines urges caution in applying lessons from one context to another [48,50-54], and we accordingly hope future research will explore the generalizability of these findings beyond our study region. That said, we note that this study encompasses a fairly large dataset covering diverse communities across a six-county region, and the nature of our key findings suggests the importance of considering more sophisticated approaches to modeling relationships 
among variables such as risk perceptions and mitigation decisions, regardless of the specific context under investigation.

How likely respondents think it is that fire will burn on their property in the first place, and the expected consequences to one's home if that happens, are also related to the results of wildfire hazard modeling, although the effect relates to burn probability only, not conditional fire intensity level, and attenuates strongly and even reverses at higher burn probabilities, as reflected by the negative coefficients on burn probability squared. For the main effect for perceived hazard rating, this could reflect either residents' awareness of the results of the fire modeling products or an understanding of the basic physical processes and conditions represented in these models. However, the results for the perceived vulnerability or expected consequences rating, as well as for the second order term for burn probability, are contrary to lessons of fire science, which associate fire intensities with the likelihood of structural ignition. Further, increasing simulated fire intensity level is only weakly associated with higher parcel-level risk conditions. This could reflect that these conditions are generally associated with denser fuels, which are typically more difficult and costlier to conduct mitigation on, or it could reflect that the data underlying the simulated fire intensity level captures some relevant variation in parcel-level conditions. Accordingly, future research further investigating residents' understandings of fire wildfire hazards could prove illuminating. Either way, this suggests that increasing the public availability of wildfire risk-related assessment products-especially those focused on the specific hazard and risks faced on an individual property - may indeed hold potential for increasing mitigation actions among residents whose homes are situated in areas with high wildfire hazard. This is similar to Olsen et al. [29], who found risk perceptions positively correlated with hazardous conditions but only weakly predicting mitigation actions. As an aside, we also note that results shown in Table 4 are consistent with a replication that omits the BP and FIL variables, demonstrating that our main results do not depend on controlling for these simulated fire hazard measures.

These findings suggest an important area of further education for WUI residents would be toward improved understanding of the relationship between fire behavior, including intensity levels, and the associated challenges of wildfire suppression and the consequences that a fire would have to one's home if it occurs. In turn, this improved understanding could strengthen the linkage between the perceived chances of losing one's home and the decision to undertake mitigation actions. This could offer another channel of influence upon mitigation actions beyond attempting to change perceptions of the chance of a wildfire burning onto one's property and addressing stated barriers to risk mitigation, such as the need for better slash removal options. That said, we find that mitigation levels are lower among residents facing time constraints, among those who do not think that risk reduction actions are effective, and among those who perceive a lack of options for slash (or yard waste) removal. As such, our results suggest that programs that subsidize mitigation work through cost sharing and community chipper days, for example, or that provide targeted education on how to conduct wildfire risk mitigation effectively, could lead to greater mitigation levels.

Finally, in another difference between models, the naïve, separate models produce the result that nearby fires are associated with a lower perceived chance of fire damaging home, which could mistakenly lead to the conclusion that residents are learning that fires are not as dangerous as they might have otherwise thought, a phenomenon described as a "resilient near miss" by Tinsley et al. [55]. However, the simultaneous model suggests that rather than convincing residents that fires are less dangerous than they thought, knowledge of nearby past fires acts only indirectly upon perceived consequences: through increasing the perceived probability of a fire on one's property, nearby fires indirectly are associated with greater parcel-level mitigation, and this increased mitigation subsequently lowers perceived consequences. This more complex chain is more consistent with Tinsley et al.'s "vulnerable near miss" mechanism, in which a past event serves as a wake-up call and encourages mitigation. 


\section{Conclusions}

In conclusion, using a simultaneous model and multiple data sources, we find strong evidence of dual-directional interactions among assessed landscape-level conditions, risk perceptions, and mitigation activity. We find evidence supporting the use of assessed parcel conditions as a measure of mitigation activity, at least at the gross level measured by a rapid assessment approach. These findings underscore the important point that estimation of correlations and simplified reduced form models can mislead, particularly when considering phenomena as complex as human decision-making in the presence of risk. Our results demonstrate that residents living in areas exposed to wildfire hazards tend to have a relatively sophisticated understanding of their risk, and their decisions about risk mitigation actions are determined in part by perceptions of the wildfire hazard, as well as their perceived barriers and efficacy of mitigation.

Author Contributions: Conceptualization, J.R.M., H.B.-S., P.C., J.G., L.F., and C.B.; Data curation, J.R.M., J.G., and L.F.; Formal analysis, J.R.M.; Funding acquisition, J.R.M., H.B.-S., P.C., J.G., L.F., and C.B.; Methodology, J.R.M., H.B.-S., P.C., J.G., L.F., and C.B.; Writing-original draft, J.R.M. and H.B.-S.; Writing一review \& editing, J.R.M., P.C., and C.B.

Funding: This research was funded by the U.S. Joint Fire Science Program (Project ID 14-2-01-31), the U.S. Interagency National Fire Plan, and in-kind by the authors' institutions.

Acknowledgments: We thank WRWC and FSC for providing survey and assessment data. This manuscript was improved by constructive comments provided by Jude Bayham (Colorado State University) and anonymous reviewers selected by the journal.

Conflicts of Interest: The authors declare no conflict of interest. The funders had no role in the design of the study; in the collection, analyses, or interpretation of data; in the writing of the manuscript, or in the decision to publish the results.

\section{References}

1. Cohen, J. The wildland-urban interface fire problem: A consequence of the fire exclusion paradigm. For. Hist. Today 2008, Fall, 20-26.

2. Cohen, J.D. Preventing disaster: Home ignitability in the wildland-urban interface. J. For. 2000, 3, 15-21.

3. Cohen, J.D. Structure ignition assessment model (SIAM). In Proceedings of the The Biswell Symposium: Fire Issues and Solutions in Urban Interface and Wildland Ecosystems, Walnut Creek, CA, USA, 15-17 February 1994; Weise, D.R., Martin, R.E., Eds.; Pacific Southwest Research Station, Forest Service, U.S. Department of Agriculture: Albany, CA, USA, 1995; pp. 85-92.

4. Cohen, J.D.; Stratton, R.D. Home Destruction Examination: Grass Valley Fire, Lake Arrowhead, California; U.S. Department of Agriculture, Forest Service, Pacific Southwest Region (Region 5): Vellejo, CA, USA, 2008; p. 26.

5. Graham, R.T. Hayman Fire Case Study; U.S. Department of Agriculture, Forest Service, Rocky Mountain Research Station: Fort Collins, CO, USA, 2003.

6. Maranghides, A.; McNamara, D.; Mell, W.; Trook, J.; Toman, B. A Case Study of a Community Affected by the Witch and Guejito Fires: Report \#2-Evaluating the Effects of Hazard Mitigation Actions on Structure Ignitions; National Institute of Standards and Technology: Gaithersburg, MD, USA, 2013.

7. Quarles, S.L.; Valachovic, Y.; Nakamura, G.M.; Nader, G.A.; de Lasaux, M.J. Home Survival in Wildfire-Prone Areas: Building Materials and Design Considerations; University of California, Agriculture and Natural Resources: Davis, CA, USA, 2010; ISBN 978-1-60107-693-9.

8. Gill, A.M.; Stephens, S.L. Scientific and social challenges for the management of fire-prone wildland-urban interfaces. Environ. Res. Lett. 2009, 4, 034014. [CrossRef]

9. Gibbons, P.; van Bommel, L.; Gill, A.M.; Cary, G.J.; Driscoll, D.A.; Bradstock, R.A.; Knight, E.; Moritz, M.A.; Stephens, S.L.; Lindenmayer, D.B. Land Management Practices Associated with House Loss in Wildfires. PLOS ONE 2012, 7, e29212. [CrossRef]

10. Kolden, C.A.; Henson, C. A Socio-Ecological Approach to Mitigating Wildfire Vulnerability in the Wildland Urban Interface: A Case Study from the 2017 Thomas Fire. Fire 2019, 2, 9. [CrossRef] 
11. Penman, S.H.; Price, O.F.; Penman, T.D.; Bradstock, R.A. The role of defensible space on the likelihood of house impact from wildfires in forested landscapes of south eastern Australia. Int. J. Wildland Fire 2019, $28,4$. [CrossRef]

12. Scott, J.H.; Thompson, M.P.; Gilbertson-Day, J.W. Examining alternative fuel management strategies and the relative contribution of National Forest System land to wildfire risk to adjacent homes-A pilot assessment on the Sierra National Forest, California, USA. For. Ecol. Manag. 2016, 362, 29-37. [CrossRef]

13. Syphard, A.D.; Brennan, T.J.; Keeley, J.E. The importance of building construction materials relative to other factors affecting structure survival during wildfire. Int. J. Disaster Risk Reduct. 2017, 21, 140-147. [CrossRef]

14. Syphard, A.D.; Brennan, T.J.; Keeley, J.E. The role of defensible space for residential structure protection during wildfires. Int. J. Wildland Fire 2014, 23, 1165. [CrossRef]

15. Jolley, A. Does Wildfire Mitigation Work? 16 Examples and Counting! Fire Adapt. Communities Learn. Netw. 2018. Available online: https://fireadaptednetwork.org/does-wildfire-mitigation-work-16-examples-andcounting/ (accessed on 7 August 2019).

16. Theobald, D.M.; Romme, W.H. Expansion of the US wildland-Urban interface. Landsc. Urban Plan. 2007, 83, 340-354. [CrossRef]

17. Dennison, P.E.; Brewer, S.C.; Arnold, J.D.; Moritz, M.A. Large wildfire trends in the western United States, 1984-2011. Geophys. Res. Lett. 2014, 41, 2928-2933. [CrossRef]

18. Westerling, A.L. Warming and Earlier Spring Increase Western U.S. Forest Wildfire Activity. Science 2006, 313, 940-943. [CrossRef]

19. Hamilton, M.; Fischer, A.P.; Guikema, S.D.; Keppel-Aleks, G. Behavioral adaptation to climate change in wildfire-prone forests. Wiley Interdiscip. Rev. Clim. Change 2018, 9, e553. [CrossRef]

20. McCaffrey, S.; Toman, E.; Stidham, M.; Shindler, B. Social science research related to wildfire management: An overview of recent findings and future research needs. Int. J. Wildland Fire 2013, 22, 15. [CrossRef]

21. Brenkert-Smith, H.; Champ, P.A.; Flores, N. Trying not to get burned: Understanding homeowners' wildfire risk-mitigation behaviors. Environ. Manag. 2012, 50, 1139-1151. [CrossRef]

22. Fischer, A.P.; Kline, J.D.; Ager, A.A.; Charnley, S.; Olsen, K.A. Objective and perceived wildfire risk and its influence on private forest landowners' fuel reduction activities in Oregon's (USA) ponderosa pine ecoregion. Int. J. Wildland Fire 2014, 23, 143. [CrossRef]

23. Martin, W.E.; Martin, I.M.; Kent, B. The role of risk perceptions in the risk mitigation process: The case of wildfire in high risk communities. J. Environ. Manag. 2009, 91, 489-498. [CrossRef]

24. McFarlane, B.L.; McGee, T.K.; Faulkner, H. Complexity of homeowner wildfire risk mitigation: An integration of hazard theories. Int. J. Wildland Fire 2011, 20, 921. [CrossRef]

25. Brenkert-Smith, H.; Champ, P.A.; Flores, N. Insights into wildfire mitigation decisions among wildland-urban interface residents. Soc. Nat. Resour. 2006, 19, 759-768. [CrossRef]

26. Dickinson, K.; Brenkert-Smith, H.; Champ, P.; Flores, N. Catching fire? Social interactions, beliefs, and wildfire risk mitigation behaviors. Soc. Nat. Resour. 2015, 28, 807-824. [CrossRef]

27. McGee, T.K.; Russell, S. "It's just a natural way of life ... " An investigation of wildfire preparedness in rural Australia. Environ. Hazards 2003, 5, 1-12. [CrossRef]

28. Brenkert-Smith, H. Building bridges to fight fire: The role of informal social interactions in six Colorado wildland-Urban interface communities. Int. J. Wildland Fire 2010, 19, 689. [CrossRef]

29. Olsen, C.S.; Kline, J.D.; Ager, A.A.; Olsen, K.A.; Short, K.C. Examining the influence of biophysical conditions on wildland-urban interface homeowners' wildfire risk mitigation activities in fire-prone landscapes. Ecol. Soc. 2017, 22. [CrossRef]

30. Champ, P.A.; Donovan, G.H.; Barth, C.M. Living in a tinderbox: Wildfire risk perceptions and mitigating behaviours. Int. J. Wildland Fire 2013, 22, 832. [CrossRef]

31. Nagle, M.G. Wildfire Risk Perception and Homeowner Mitigation: Evidence from Montana. Master's Thesis, University of Montana, Missoula, MT, USA, 2018.

32. Short, K.C.; Finney, M.A.; Scott, J.H.; Gilbertson-Day, J.W.; Grenfell, I.C. Spatial Dataset of Probabilistic Wildfire Risk Components for the Conterminous United States; U.S. Department of Agriculture: Washington, DC, USA, 2016; Forest Service Research Data Archive. [CrossRef]

33. Paveglio, T.B.; Edgeley, C.M.; Stasiewicz, A.M. Assessing influences on social vulnerability to wildfire using surveys, spatial data and wildfire simulations. J. Environ. Manag. 2018, 213, 425-439. [CrossRef] 
34. King, M.F.; Bruner, G.C. Social desirability bias: A neglected aspect of validity testing. Psychol. Mark. 2000, 17, 79-103. [CrossRef]

35. Van de Mortel, T. Faking it: Social desirability response bias in self-report research. Aust. J. Adv. Nurs. 2008, $25,40-48$.

36. Meldrum, J.R.; Champ, P.A.; Brenkert-Smith, H.; Warziniack, T.; Barth, C.M.; Falk, L.C. Understanding gaps between the risk perceptions of wildland-urban interface (wui) residents and wildfire professionals: Wui residents and wildfire professionals. Risk Anal. 2015, 35, 1746-1761. [CrossRef]

37. Economic Profile System (EPS). Headwaters Economics. Available online: https://headwaterseconomics.org/ tools/economic-profile-system/about/ (accessed on 7 August 2019).

38. Fire Adapted Communities Learning Network. Promoting Fire Adapted Communities Through Property Assessments: Data \& Tools. 2015. Available online: https://fireadaptednetwork.org/resource/promoting-fireadapted-communities-through-property-assessments-data-tools/ (accessed on 7 August 2019).

39. Brenkert-Smith, H.; Meldrum, J.R.; Wilson, P.; Champ, P.A.; Barth, C.M.; Boag, A. Living with Wildfire in Montezuma County, Colorado: 2015 Data Report; U.S. Department of Agriculture, Forest Service, Rocky Mountain Research Station: Fort Collins, CO, USA, 2019; p. 36.

40. Brenkert-Smith, H.; Meldrum, J.R.; Wilson, P.; Champ, P.A.; Barth, C.M.; Boag, A. Living with Wildfire in La Plata County, Colorado: 2015 Data Report; U.S. Department of Agriculture, Forest Service, Rocky Mountain Research Station: Fort Collins, CO, USA, 2019; p. 36.

41. Meldrum, J.R.; Brenkert-Smith, H.; Wilson, P.; Champ, P.A.; Barth, C.M.; Boag, A. Living with Wildfire in Archuleta County, Colorado: 2015 Data Report; U.S. Department of Agriculture, Forest Service, Rocky Mountain Research Station: Fort Collins, CO, USA, 2019; p. 36.

42. Meldrum, J.R.; Colter Falk, L.; Gomez, J.; Barth, C.; Brenkert-Smith, H.; Warziniack, T.; Champ, P.A. Living with Wildfire in Telluride Fire Protection District, Colorado; U.S. Department of Agriculture, Forest Service, Rocky Mountain Research Station: Fort Collins, CO, USA, 2017; p. 30.

43. Meldrum, J.R.; Barth, C.; Colter Falk, L.; Brenkert-Smith, H.; Warziniack, T.; Champ, P.A. Living with Wildfire in Delta County, Colorado: Cross-Community Comparisons; U.S. Department of Agriculture, Forest Service, Rocky Mountain Research Station: Fort Collins, CO, USA, 2015; p. 33.

44. Meldrum, J.R.; Barth, C.M.; Falk, L.C.; Brenkert-Smith, H.; Warziniack, T.; Champ, P. Living with Wildfire in Log Hill Mesa, Colorado; U.S. Department of Agriculture, Forest Service, Rocky Mountain Research Station: Fort Collins, CO, USA, 2013; p. 34.

45. Finney, M.A.; McHugh, C.W.; Grenfell, I.C.; Riley, K.L.; Short, K.C. A simulation of probabilistic wildfire risk components for the continental United States. Stoch. Environ. Res. Risk Assess. 2011, 25, 973-1000. [CrossRef]

46. Zellner, A.; Theil, H. Three-Stage Least Squares: Simultaneous Estimation of Simultaneous Equations. Econometrica 1962, 30, 54. [CrossRef]

47. Warziniack, T.; Champ, P.; Meldrum, J.; Brenkert-Smith, H.; Barth, C.M.; Falk, L.C. Responding to Risky Neighbors: Testing for Spatial Spillover Effects for Defensible Space in a Fire-Prone WUI Community. Environ. Resour. Econ. 2019, 73, 1023-1047. [CrossRef]

48. Meldrum, J.R.; Brenkert-Smith, H.; Champ, P.A.; Falk, L.; Wilson, P.; Barth, C.M. Wildland-urban interface residents' relationships with wildfire: Variation within and across communities. Soc. Nat. Resour. 2018, 31, 1-17. [CrossRef]

49. Drukker, D.M.; Prucha, I.R.; Raciborski, R. A command for estimating spatial-autoregressive models with spatial-autoregressive disturbances and additional endogenous variables. Stata J. 2013, 13, $287-301$. [CrossRef]

50. Paveglio, T.B.; Jakes, P.J.; Carroll, M.S.; Williams, D.R. Understanding Social Complexity Within the Wildland-Urban Interface: A New Species of Human Habitation? Environ. Manag. 2009, 43, 1085-1095. [CrossRef]

51. Gordon, J.S.; Luloff, A.; Stedman, R.C. A Multisite Qualitative Comparison of Community Wildfire Risk Perceptions. J. For. 2012, 110, 74-78. [CrossRef]

52. Moritz, M.A.; Batllori, E.; Bradstock, R.A.; Gill, A.M.; Handmer, J.; Hessburg, P.F.; Leonard, J.; McCaffrey, S.; Odion, D.C.; Schoennagel, T. Learning to coexist with wildfire. Nature 2014, 515, 58. [CrossRef]

53. Stidham, M.; McCaffrey, S.; Toman, E.; Shindler, B. Policy tools to encourage community-level defensible space in the United States: A tale of six communities. J. Rural Stud. 2014, 35, 59-69. [CrossRef] 
54. McLennan, J.; Paton, D.; Wright, L. At-risk householders' responses to potential and actual bushfire threat: An analysis of findings from seven Australian post-bushfire interview studies 2009-2014. Int. J. Disaster Risk Reduct. 2015, 12, 319-327. [CrossRef]

55. Tinsley, C.H.; Dillon, R.L.; Cronin, M.A. How Near-Miss Events Amplify or Attenuate Risky Decision Making. Manag. Sci. 2012, 58, 1596-1613. [CrossRef] 